\title{
FUNGOS MICORRÍZICOS ARBUSCULARES EM SOLOS SOB DIFERENTES CULTIVOS
}

Ana Maria Sá Durazzini - IFET Sul de Minas Gerais - Campus de Inconfidentes, Jamil de Morais Pereira - IFET Sul de Minas Gerais - Campus de Inconfidentes, Luiz Carlos Dias Rocha - IFET Sul de Minas Gerais - Campus de Inconfidentes, Ademir José Pereira - IFET Sul de Minas Gerais - Campus de Inconfidentes

\section{RESUMO}

O presente trabalho teve como objetivo estudar a ocorrência de FMAs em diferentes áreas na Fazenda Experimental do Instituto Federal de Educação, Ciência e Tecnologia Sul de Minas Gerais Campus de Inconfidentes, em dois períodos distintos: seco (abril/setembro) e chuvoso (outubro/março). Foram amostradas áreas sob cultivo de café, pastagem, banana, citros, horta, pinus e eucalipto (uma cultura com dois e outra com quarenta anos de desenvolvimento), uma área sob implantação de mata ciliar, e uma outra área ocupada por mata nativa. Para cada uma das amostras de solo coletadas na camada de $0-20 \mathrm{~cm}$ realizou-se a extração de esporos em quatro repetições, adotando-se a técnica do peneiramento úmido seguido de centrifugação em sacarose a 50\%. A contagem dos esporos foi realizada por meio de uma placa canaletada com auxílio de microscópio estereoscópico. Houve variação na densidade de esporos de FMAs nos solos sob diferentes cultivos nos dois períodos estudados (seco e chuvoso). A maior e a menor densidade de esporos foram obtidas no solo sob cultivo, respectivamente de pastagem e pinus no período seco. No período chuvoso a maior e a menor densidade de esporos foi observada no solo sob cultivo do citros e pinus respectivamente. Houve interação significativa em relação aos períodos estudados para densidade de esporos nos solos sob cultivo de pastagem e eucalipto. O período seco apresentou maiores densidades de esporos quando relacionados às áreas sob cultivo de café, banana, horta, pastagem, eucalipto, mata ciliar e citros. As práticas de manejo adotadas em cada área também tiveram influência na densidade de esporos.

Palavras-chave: FMAs, peneiramento úmido, esporos.

\section{INTRODUÇÃO}

A associação micorrízica é de fundamental importância no estabelecimento e crescimento das plantas de diversas espécies florestais e agrícolas, principalmente em ambientes de solos pobres em minerais e degradados. O principal benefício às plantas decorre da estrutura formada pelas hifas de fungos do solo e raízes de plantas, proporcionando aumento no volume de solo explorado pelas raízes. Entre essas interações está o estabelecimento de associações simbióticas com fungos, das subdivisões Basidiomycotina ou Ascomycotina, formando as ectomicorrizas e também por um grupo de fungos pertencentes à Ordem Glomerales do filo Glomeromycota (STÜRMER \& SIQUEIRA, 2006) dos Zigomicetos, formando as endomicorrizas do tipo arbuscular. Nestas associações ocorre uma íntima interação entre os simbiontes, desenvolvendo uma perfeita interação morfológica e fisiológica, resultando em alta compatibilidade funcional, que pode favorecer o crescimento e o desenvolvimento das plantas, pelo aumento da área explorada pelo sistema radicular, resultando em melhor capacidade de absorção de água e elementos minerais do solo, principalmente o fósforo.

As micorrizas são de interesse especial para o Brasil, devido à baixa fertilidade dos solos e elevado requerimento de nutrientes pela maioria das culturas. Outros fatores como condições ambientais estressantes, alta proporção de minifundiários com pequeno poder aquisitivo, suprimento limitado de fertilizantes em certas áreas, sistemas de monocultura, possível exaustão dos depósitos de fosfatos e preocupação crescente com a qualidade ambiental, visando minimizar os 
impactos da poluição do solo e da água, e do desmatamento sobre o ambiente, também são de grande interesse.

A utilização de microorganismos como aprimoramento tecnológico tendo como finalidade melhorar a disponibilidade de nutrientes às plantas, é uma prática potencial de grande importância e muito necessária para a agricultura. É fato comprovado que os benefícios das micorrizas para as plantas são diversos, mas há indicações que, dependendo do manejo adotado nas culturas, a diversidade de espécies e o potencial de inóculo natural local podem sofrer alterações.

\section{OBJETIVO}

O objetivo deste trabalho foi estudar a ocorrência de fungos micorrízicos arbusculares (FMAs) em solos sob diferentes cultivos na Fazenda Experimental (FEIFETCampus Inconfidentes), em dois períodos distintos: seco e chuvoso.

\section{MATERIAL E MÉTODOS}

\section{Descrição do local de realização do trabalho}

O trabalho foi realizado no município de Inconfidentes - Minas Gerais, na Fazenda Experimental do Instituto Federal de Educação Ciência e Tecnologia Sul de Minas Gerais (FEIFET - Campus Inconfidentes), situada na latitude $22^{\circ} 19^{\prime} 1,2^{\prime \prime} \mathrm{S}$, longitude $46^{\circ}$ $19^{\prime} 40,8^{\prime \prime} \mathrm{W}$, altitude média de $855 \mathrm{~m}$. O clima da região, segundo classificação de KOEPPEN (1931), é do tipo tropical úmido, com duas estações definidas: chuvosa (outubro/março) e seca (abril/setembro), com precipitação pluviométrica média anual de $1500 \mathrm{~mm}$ e temperatura média de $19^{\circ} \mathrm{C}$.

\section{Amostragem dos solos em estudo}

Foram realizadas duas amostragens em cada área de estudo, sendo a primeira em $18 \mathrm{e}$ 19 de abril de 2007 (período seco), e a segunda em 19 e 20 de novembro de 2007 (período chuvoso). As áreas de estudo foram: café, pastagem, banana, citros, horta, pinus, eucalipto 1, eucalipto 2, mata ciliar e mata nativa. Em cada uma dessas áreas, foi selecionado um quadrante de $1000 \mathrm{~m}^{2}$ segundo metodologia de SILVA(2007).

Nas culturas de café, banana e citros, foram amostrados aleatoriamente 10 pontos por cultura. Em cada ponto foram retiradas quatro sub-amostras, na projeção da copa da planta, a uma profundidade de $0-20 \mathrm{~cm}$ em cada quadrante da planta. Nas culturas de Pinus sp., Eucaliptus sp., pastagem, horta, áreas sob implantação de mata ciliar e áreas ocupadas por mata nativa, as amostras foram retiradas em 10 pontos distribuídos aleatoriamente no solo sob o cultivo. As amostras compostas (pelas 10 amostras simples retiradas de cada área) geraram aproximadamente $1 \mathrm{~kg}$ de solo cada. Em seguida foram acondicionadas em sacos plásticos, colocadas em caixa térmica e transportadas para o Laboratório de Biotecnologia da IFET/SMG - Campus Inconfidentes, onde foram armazenadas a $5^{\circ} \mathrm{C}$ em geladeira, até o processamento.

Antes da primeira amostragem para quantificar a ocorrência e distribuição de FMAs, foram retiradas amostras na profundidade de $0-20 \mathrm{~cm}$ para caracterização química dos solos sob as áreas em estudo. Também foi realizado um levantamento de dados referentes a estas áreas, a fim de possibilitar uma melhor interpretação e aplicação dos resultados.

\section{Área sob cultivo de café}

A área em estudo está localizada na latitude $22^{\circ} 18^{\prime} 34,6^{\prime \prime} \mathrm{S}$, longitude $46^{\circ} 20^{\prime} 11,5^{\prime \prime}$ W. Existe há quarenta anos e é constituída pela variedade Icatu Amarelo, com espaçamento de $2,5 \mathrm{~m} \times 2 \mathrm{~m}$. A área recebe adubações anuais (450g do formulado 20:05:20 por planta). O solo foi classificado como Argissolo Vermelho distrófico (PRADO, 2005) e apresenta declividade média de $20 \%$. 


\section{Área sob cultivo de pastagem}

O solo estudado sob pastagem está localizado na latitude $22^{\circ} 18^{\prime} 44^{\prime \prime} \mathrm{S}$, longitude $46^{\circ} 20^{\prime} 10,4^{\prime \prime} \mathrm{W}$, e recebe adubações e calagens anuais de acordo com os resultados de análises químicas realizadas. O mesmo é suporte para Brachiaria sp., destinada à alimentação de bovinos de corte e existe há vinte anos, sendo que no início do cultivo, foi suporte de um experimento relacionado com aplicações de diferentes níveis de calcário e o desenvolvimento da gramínea. A área apresenta declividade média de $20 \%$ e o solo foi classificado como Argissolo Vermelho Eutrófico (PRADO, 2005). As amostragens foram realizadas sem a presença de animais pastando no local.

\section{Área sob cultivo de banana}

O bananal sobre o solo em estudo localiza-se na latitude $22^{\circ} 18^{\prime} 30,1^{\prime \prime} \mathrm{S}$, longitude $46^{\circ} 20^{\prime} 11,1^{\prime \prime} \mathrm{W}$, existe há quarenta anos desde a sua implantação, constituindo-se da espécie Musa cavendishii (banana-nanica), em espaçamento inicial de $4 \mathrm{~m} \times 4 \mathrm{~m}$. A declividade média da área é de $25 \%$. O solo foi classificado como Argissolo Amarelo Eutrófico (PRADO, 2005), sendo que o mesmo recebe adubações químicas anuais, com $1 \mathrm{~kg}$ do formulado NPK 20:0:20. A área apresenta, além do bananal, espécies nativas da região, tais como: Schinus terebintifolia (Pimenteira), Bauhinia forficata (Pata-devaca), Aspidosperma parviflorum (Guatambu), Oreopanax fulvum (Falsaembaúba), Geonoma (Guaricanga), Cordia ecalycrelata (Café-de-bugre), Jacaratia spinosa (Jaracatiá), Alchornea glandulosa (Tapiá), Croton floribundos (Capixingui), Platycyamum regnellii (Pau-pereira), Casearia silvestris (Guassatonga) e Tibouchina candolleana (Quaresmeira-roxa) convivendo no mesmo espaço.

\section{Área sob cultivo de citros}

A área em estudo localizava-se na latitude $22^{\circ} 18^{\prime} 36,8^{\prime \prime} \mathrm{S}$, longitude $46^{\circ} 20^{\prime} 8,9^{\prime \prime}$
W, tendo o solo classificado como Argissolo Vermelho Distrófico (PRADO, 2005). O pomar possuía 20 anos de existência e, talvez por esse motivo, foi removido da área após a primeira amostragem para a quantificação da ocorrência e distribuição de FMA. Na primeira amostragem, apresentava Citrus limonia (limão), Citrus sinensis (laranja-doce), Citrus aurantium (laranja-azeda) e Citrus reticulata (tangerina). As adubações e as calagens realizadas eram realizadas de forma irregular, assim como as análises químicas do solo.

$\mathrm{Na}$ segunda amostragem, a incidência de gramíneas do tipo Brachiaria sp predominava no local, que apresenta declividade média de $25 \%$.

\section{Área sob cultivo de horta}

A horta da FEIFET-Campus Inconfidentes localiza-se $100 \mathrm{~m}$ após a ponte de acesso da mesma, em uma área de várzea, na latitude $22^{\circ} 18^{\prime} 47,6^{\prime \prime} \mathrm{S}$, longitude $46^{\circ} 19^{\prime} 50,4^{\prime \prime}$ W. Apresenta declividade média de $2 \%$, está instalada no local há 20 anos e possui muitas variações das espécies ali cultivadas. Há a aplicação tanto de fertilizantes químicos quanto orgânicos, de acordo com o ciclo das diferentes espécies. As amostragens realizadas foram retiradas sobre os canteiros de Nasturtium officinale (agrião), Lactuca sativa (alface), Beta vulgaris (beterraba), Daucus carota (cenoura), Cichorium intybus (chicória), Pisum sativum (ervilha), Brassica oleracea (repolho), Hibiscus esculentus (quiabo). $\mathrm{O}$ solo foi classificado como Gleissolo Háplico Tb Eutrófico (PRADO, 2005).

\section{Área sob cultivo de pinus}

O solo sob cultivo de P. elliotti foi classificado como Cambissolo Háplico Tb Distrófico (PRADO, 2005). O cultivo existe há 25 anos e apresenta um espaçamento de $2,5 \mathrm{~m} \mathrm{x}$ $2 \mathrm{~m}$. A área estudada está localizada na latitude 
$22^{\circ} 18^{\prime} 46,3^{\prime \prime} \mathrm{S}$, longitude $46^{\circ} 19^{\prime} 44,3^{\prime \prime} \mathrm{W}$, com uma declividade média de $30 \%$.

\section{Área sob cultivo de eucalipto 1}

A área estudada está localizada na latitude $22^{\circ} 18^{\prime} 52,2^{\prime \prime}$ S, longitude $46^{\circ} 20^{\prime} 10,9^{\prime \prime}$ W e constitui-se de Eucalyptus grandis há quarenta anos, com o espaçamento inicial de $4 \mathrm{~m} \times 2 \mathrm{~m}$. A declividade média da área amostrada é igual a $15 \%$. O cultivo não recebe adubações e tratos culturais, apresentando também espécies arbóreas nativas da região, tais como: Aspidosperma parviflorum (Guatambu), Geonoma (Guaricanga), Jacaratia spinosa (Jaracatiá), Erythroxiillum descidum (Sessenta-e-dois), Croton floribundos (Capixingui), Casearia obliqua (Guassatonga), Cassia ferruginea (Canafistula), Erytrhyna falcata (Moxoco), Bauhinia forficata (Pata-de-vaca), Luetzelburgia guaissara (Guaissara), Machaerium aculeatum (Jacarandazinho), Machaerium stipitatum (Sapuva), Machaerium villosum (Jacarandá), Acacia polyphylla (Monjoleiro), Piptadenia gonoacantha (Pau-jacaré), Persea pyrifolia (Massaranduba), Tibouchina candolleana (Quaresmeira-roxa), Cabralea canerana (Canjarana), Zanthoxylum rhoifolium (Mamica-de-porca), Allophylus edulis (Caféde-bugre), Matayba elaeagnoides (Papagaeiro), Trema micranhta (Paupólvora). Essas espécies citadas estão se tornando dominantes na área, devido à ausência de qualquer tipo de manejo e a existência de fragmentos florestais nativos próximos. O solo foi classificado como Cambissolo Háplico Tb distrófico (PRADO, 2005).

\section{Área sob cultivo de eucalipto 2}

A área em estudo localiza-se na latitude $22^{\circ} 18^{\prime} 39,7^{\prime \prime} \mathrm{S}$, longitude $46^{\circ} 19^{\prime} 52,0^{\prime \prime}$ $\mathrm{W}$, apresenta declividade média de $25 \%$, e uma plantação de Eucalyptus urophilla, com o espaçamento de $3 \mathrm{~m} \times 2 \mathrm{~m}$, tendo dois anos de idade, sendo adubada convencionalmente no plantio e em cobertura. O manejo do mato foi realizado com roçadora mecânica durante os primeiros 18 meses de idade. O solo do local foi classificado como Argissolo Vermelho Distrófico (PRADO, 2005).

\section{Área sob implantação de mata ciliar}

Está localizada próximo à ponte de acesso à FEIFET - Campus Inconfidentes, na latitude $22^{\circ} 18^{\prime} 51,7^{\prime \prime} \mathrm{S}$, longitude $46^{\circ} 19^{\prime} 49,7^{\prime \prime}$ $\mathrm{W}$ e às margens do Rio Mogi-Guaçu, que é o divisor natural da cidade de Inconfidentes e da FEIFET - Campus Inconfidentes. Nesta área realizou-se o plantio de espécies nativas da região, tais como: Morus sp. (Amoreira), Schizolobium parahyba (Guapuruvu), Eugenia uniflora (Pitanga), Myrciaria cauliflorum (Jaboticaba), Cróton urucurana (Sangra-d’água), Campomanesia xanthocarpa (Gabiroba), Psidium guayava (Goiabeira), Cedrela odorata (Cedro-dobrejo), Chorisia speciosa (Painera), Luehea divaricata (Açoita-cavalo), Talauma ovata (Pinha-do-brejo), Inga vera (Ingá-do-rio), iniciando-se juntamente com a criação do Curso Tecnólogo em Gestão Ambiental na Agropecuária há 3 anos. O plantio foi realizado com o espaçamento de $3 \mathrm{~m}$ x $2 \mathrm{~m}$, sem adubação e com o cuidado de dispor corretamente plantas clímax e pioneiras (o modelo de plantio foi aleatório). Antes do plantio da mata ciliar, a área foi utilizada como suporte para culturas anuais instaladas e mantidas sob sistema convencional de produção. O solo em estudo foi classificado como Gleissolo Háplico Tb distrófico (PRADO, 2005), e a declividade média do local é de $2 \%$.

\section{Área ocupada por mata nativa}

A mata sobre a área em estudo caracteriza-se como secundária semi-decídua, localizada na latitude $22^{\circ} 18^{\prime} 23,4^{\prime \prime} \mathrm{S}$, longitude $46^{\circ} 19^{\prime} 50,2^{\prime \prime} \mathrm{W}$. A área apresenta declividade média de $30 \%$ e as seguintes espécies: Aspidosperma parviflorum (Guatambu), 
Geonoma (Guaricanga), Jacaratia spinosa (Jaracatiá), Cecropia hololeuca (Embaúbabranca), Erythroxiillum descidum (Sessenta-e-dois), Croton floribundos (Capixingui), Casearia obliqua (Guassatonga), Cassia ferruginea (Canafistula), Erytrhyna falcata (Moxoco), Bauhinia forficata (Pata-de-vaca), Luetzelburgia guaissara (Guaissara), Machaerium aculeatum (Jacarandazinho), Machaerium stipitatum (Sapuva), Machaerium villosum (Jacarandá), Ormosia arborea (Olho-de-cabra), Lonchocarpus guillemineanus (Timbó), Acacia polyphylla (Monjoleiro), Piptadenia gonoacantha (Paujacaré), Ocotea elegans (Canelinha-docampo), Ocotea odorifera (Sassafrás), Persea pyrifolia (Massaranduba), Tibouchina candolleana (Quaresmeira-roxa), Cabralea canerana (Canjarana), Cedrela fissilis (Cedro), Maclura tinctoria (Taiuveira), Myrcia crassifólia (Orelha-de-onça), Myrciaria tertela (Vassoura-guamirim), Zanthoxylum rhoifolium (Mamica-de-porca), Allophylus edulis (Café-de-bugre), Matayba elaeagnoides (Papagaeiro), Trema micranhta (Pau-pólvora), Aegiphyla sellowina (Tamanqueiro), Qualea jundiahy (Pau-terra), Drimys brasiliensis (Casca-d'anta). O solo foi classificado como Argissolo Vermelho Distrófico (PRADO, 2005).

\section{Extração e quantificação dos esporos}

A primeira extração dos esporos foi realizada em 11 e 12 de agosto de 2007, e a segunda, em 26 e 27 de novembro de 2007, sendo que as amostras de cada época foram passadas em peneira com malha de $2 \mathrm{~mm}$ de diâmetro e secas ao ar por 12 horas. Em seguida, a densidade de esporos foi avaliada, utilizando-se de quatro repetições para cada área amostrada, contendo em cada repetição $50 \mathrm{~mL}$ de solo, medidos em becker de $100 \mathrm{~mL}$.

Os esporos foram extraídos pelo método do peneiramento úmido (GERDEMANN e NICOLSON, 1963).
O procedimento consistiu na transferência, separadamente, dos volumes das amostras citadas anteriormente para recipiente plástico de maior volume, onde as mesmas foram lavadas quatro vezes, sendo o sobrenadante resultante de cada lavagem, passado em peneiras de malhas $0,71,0,25$ e $0,053 \mathrm{~mm}$; o material retido na peneira de menor malha foi acondicionado diretamente em tubos de centrífuga. Em seguida, os tubos foram balanceados com água destilada e centrifugados por 3 minutos a 3000 RPM. Em seguida, o sobrenadante dos tubos foi drenado cuidadosamente, sendo adicionado aos mesmos uma solução de sacarose a $50 \%$ (JENKINS, 1964), agitando o conteúdo com auxílio de um bastão de vidro para serem centrifugados por 2 minutos a 2000 RPM. Após, o sobrenadante foi drenado com cuidado, na peneira de menor malha $(0,053$ $\mathrm{mm})$.

Posteriormente, o material foi lavado com água destilada e recolhido em 40 recipientes plásticos (4 replicatas para cada amostra) com tampa e capacidade para 100 $\mathrm{mL}$, devidamente identificados com o nome, número da amostra e a data de realização da extração. Os recipientes foram armazenados em geladeira a $5^{\circ} \mathrm{C}$ até a contagem dos esporos.

A contagem dos esporos da primeira extração foi realizada em 20 e 21 de outubro de 2007, e a segunda, em 01 e 02 de dezembro de 2007. Os mesmos foram contados diretamente em placa canaletada com o auxílio de microscópio estereoscópio, assim como realizado por SILVA(2007).

\section{Delineamento experimental}

O experimento foi conduzido em delineamento inteiramente casualizado em esquema fatorial $2 \times 10$, sendo dois períodos de coleta (seco e chuvoso) e dez áreas de estudo (café, pastagem, banana, citros, horta, pinus, eucalipto 1 , eucalipto 2 , mata ciliar e mata nativa), realizando-se quatro replicatas. Os dados foram submetidos à análise de variância (ANAVA) e as médias foram comparadas pelo 
teste de Scott-Knott a 5\% de probabilidade, usando-se o programa Sisvar 4.3 (FURTADO, 2000).

\section{RESULTADOS E DISCUSSÕES}

\section{Período seco}

A área ocupada com pastagem apresentou a maior média de esporos $/ 50 \mathrm{~mL}$ de solo $(244,0)$, diferindo-se estatisticamente das demais áreas estudadas no período seco. As áreas sob cultivo de eucalipto $2(209,75)$ e sob implantação de mata ciliar $(193,75)$ não diferiram-se estatisticamente entre si. As áreas de horta $(68,25)$, eucalipto $1(57,50)$ e mata nativa $(59,50)$ diferiram-se estatisticamente da área sob cultivo de pinus $(9,75)$, esta última com as menores médias de número de esporos. Nas áreas ocupadas com banana $(103,50)$, café $(141,25)$ e citros $(134,00)$ verificou-se valores de densidade de esporos intermediárias, sendo que na área sob cultivo de banana os valores foram inferiores estatisticamente das áreas sob cultivo de café e citros, que por sua vez, não apresentaram diferença estatística. (Figura 1).

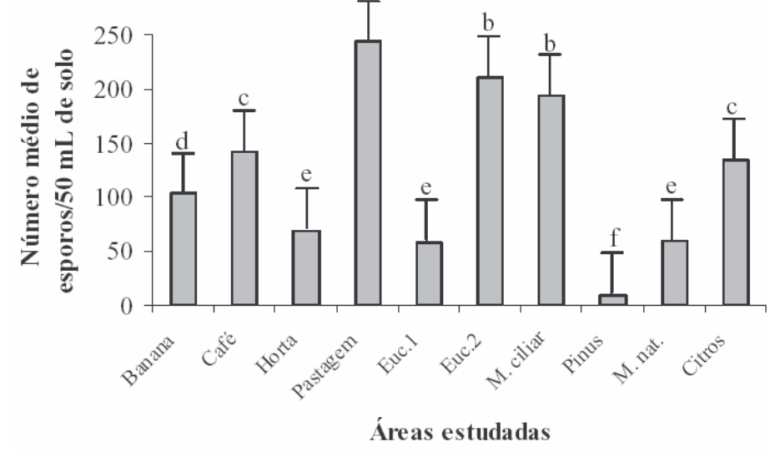

Figura 1. Número de esporos $/ 50 \mathrm{~mL}$ de solo nos solos sob diferentes cultivos no período seco (abril/setembro).

\section{Período chuvoso}

Para a época chuvosa, verificou-se que as áreas de citros $(131,75)$, café $(103,0)$, pastagem $(100,75)$ e mata ciliar $(109,75)$ tiveram os maiores valores de densidade de esporos no solo, sendo a área sob cultivo de citros diferente estatisticamente das áreas sob cultivo de café, pastagem e sob implantação de mata ciliar, que por sua vez, foram iguais estatisticamente. As áreas ocupadas com banana $(87,75)$, horta $(60,25)$, eucalipto 2 $(83,75)$ e mata nativa $(60,75)$ resultaram em densidade de esporos intermediárias e os menores valores foram observados para as áreas de eucalipto $1(41,75)$ e pinus $(17,0)$

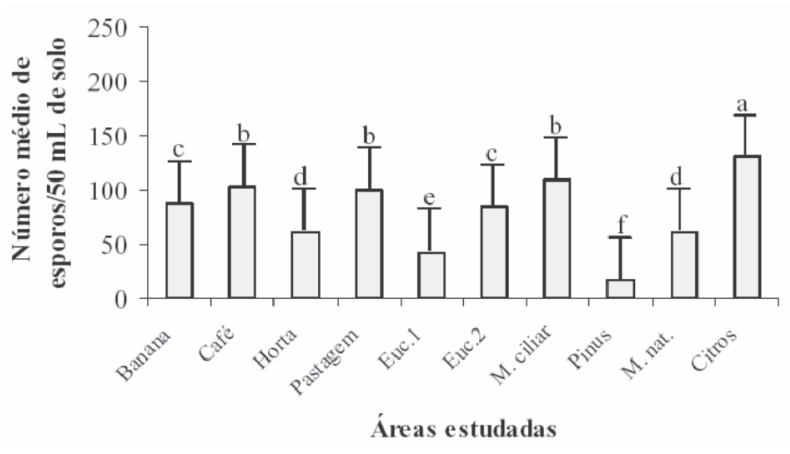

Figura 2. Número de esporos $/ 50 \mathrm{~mL}$ de solo nos solos sob diferentes cultivos no período chuvoso (outubro/março).

\section{Período seco x período chuvoso}

Em relação à sazonalidade (período seco e chuvoso), as áreas sob cultivo de banana, café, horta, eucalipto 1, mata ciliar, pinus, mata nativa e citros, não diferiram estatisticamente entre si. A maior média de número de esporos encontrados no período seco (abril/setembro), se deu na área sob cultivo de pastagem que, por sua vez, diferiu-se estatisticamente do período chuvoso. Em relação ao período chuvoso (outubro/março), a maior média do número de esporos foi obtida na área ocupada por citros, que neste período já havia sido erradicado do local. A média obtida pela área sob cultivo de eucalipto 2, diferiu-se estatisticamente entre o período seco e chuvoso.

Os números de esporos obtidos nos dois períodos estudados podem ser observados na 


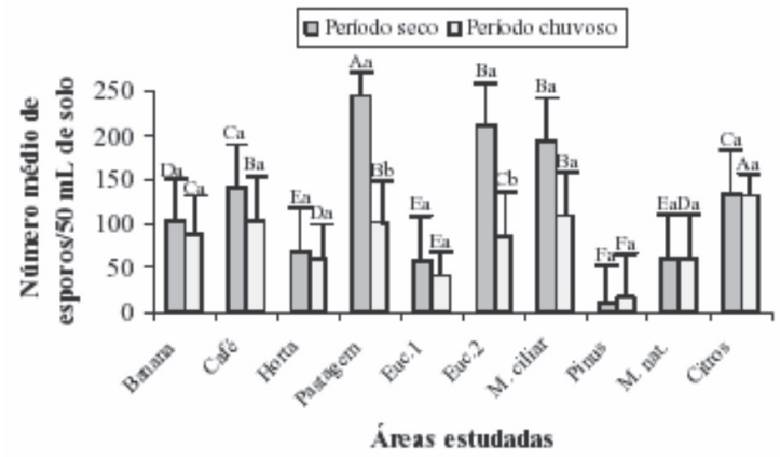

Figura 3. Número de esporos $/ 50 \mathrm{~mL}$ de solo nos solos sob diferentes cultivos no período seco e chuvoso. Médias seguidas pela mesma letra maiúscula comparam dentro dos tratamentos e seguidas pela mesma letra minúscula comparam entre os tratamentos não diferindo entre si pelo teste de Scott-Knott a $5 \%$ de probabilidade.

\section{CONCLUSÕES}

Os períodos de estudo (seco e chuvoso) influenciaram nas densidades de esporos.

O sistema de manejo adotado em cada área estudada teve influência sobre a densidade de esporos.

O período seco proporcionou os maiores valores de densidade de esporos (com exceção para as áreas de pinus e mata nativa).

O solo sob cultivo de pastagem proporcionou maior número de esporos no período seco, enquanto que no período chuvoso o maior valor foi sob cultivo de citros.

A menor densidade de esporos foi verificada no cultivo de pinus, independentemente da época estudada.

\section{BIBLIOGRAFIA}

FURTADO, D. Sistema de analise de variância: Sisvar 4.1. Lavras: UFLA/CAPES, 2000.

GERDEMANN, J.W.; NICOLSON, T.H.
Spores of mycorrhizal endogone species extracted from soil by wet sieving and decanting. Transactions of the British Mycological Society, Cambridge, v.6,p. 235246, 1963.

JENKINS, W. R. A rapid centrifugalfloatation technique for separating nematodes from soil. Plant Disease Report, v.48, n. 8,p.692-694, 1964.

KOEPPEN, W. Grundriss der Klimakunde. Zweite verbesserte auflage der "Klimate der Erde". Berlin: Walter De Gruite Co, 1931.

PRADO, H.do. Solos do Brasil: gênese, morfologia, classificação, levantamento, manejo. 4.ed. Piracicaba, 282 p., 2005.

SILVA, L.X. da.; FIGUEIREDO, M.V.B.; SILVA, G.A; GOTO, B.T.; OLIVEIRA, J.P.; BURITY, H.A. Fungos micorrízicos arbusculares em áreas de plantio de leucena e sabia na estado de Pernambuco. Revista Arvore, Viçosa, v.31, p.427-435, 2007.

STÜRMER,S.L.; SIQUEIRA, J.O. Diversity of arbuscular mycorrhizal fungi in Brazilian ecosystems. In: MOREIRA, F.M.S.; SIQUEIRA, J.O. ; BRUSSAARD, L. (Ed). Soil biodiversity in Amazonian and Brazilian ecosystems. CABI- Publishing, p.206-236, 2006. 